\title{
Renal Cortical Structural Alterations in Atorvastatin- treated Rats and the Possible Protective Mechanisms of L-Carnitine
}

\author{
SAHAR YOUSSEF* AND MARWA SALAH ${ }^{1}$
}

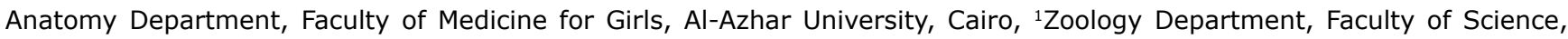
Beni-Suef University, Beni-Suef, Egypt

\author{
Youssef and Salah: Protective Mechanisms of L-Carnitine
}

\begin{abstract}
The present study investigated the structural changes in rat kidney following administration of atorvastatin and evaluated the possible protective role of L-carnitine. Rats were divided into four groups, group I- control group, group II received L-carnitine at $100 \mathrm{mg} / \mathrm{kg} / \mathrm{d}$, group III received atorvastatin at $80 \mathrm{mg} / \mathrm{kg} / \mathrm{d}$ and group IV received atorvastatin plus L-carnitine. Hematoxylin and Eosin, periodic acid-Schiff, inducible nitric oxide synthase, proliferating cell nuclear antigen expression and electron microscopy investigation were performed. Light microscopy results of atorvastatin group showed severe atrophic glomeruli with widened glomerular spaces. Some renal tubules showed cytoplasmic vacuolations, loss of brush borders, haemorrhage and mild congested blood capillaries. Strong positive inducible nitric oxide synthase and proliferating cell nuclear antigen immunostaining in the tubules were observed. Ultrastructurally, the proximal convoluted tubules had small electron dense nuclei, numerous lysosomes, partial loss of microvilli and vacuolations. The podocytes revealed united foot processes and increase in the thickness of the glomerular basement membrane. L-carnitine preserved the structure of renal cortex, decreased inducible nitric oxide synthase and increased proliferating cell nuclear antigen reaction. In conclusion, atorvastatin exerted a deleterious effect and L-carnitine improved most of the histological changes produced by atorvastatin.
\end{abstract}

Key words: Atorvastatin, kidney, PAS, iNOS, PCNA, ultrastructure

Statins are a class of the most recommended drugs prescribed for various diseases such as hypercholesterolemia, ischemic heart disease, and cerebrovascular accidents ${ }^{[1]}$. Hyperlipidemia has adverse effect on neurological outcomes that could lead to disability. Statins can reverse this risk of disability in patients treated with a lower dose ${ }^{[2]}$. High dose of statins has been recognized to be more successful in cardiovascular diseases than the lower dose. However, much concerns of threats of rhabdomyolysis, acute kidney injury, diabetes mellitus, and memory loss have been encouraged some researchers to identify more accurately the side effects of statins ${ }^{[3]}$. Statins are 3-hydroxy3-methyl-glutaryl-coenzyme A reductase inhibitors existent in several forms including atorvastatin (Lipitor) ${ }^{[4]}$. Studies have reported that atorvastatin, a lipid lowering agent, decreased vascular risk in patients with coronary artery disease by reducing plasma levels of cholesterol ${ }^{[5]}$. It has been reported that administration of atorvastatin is associated with an imbalance between pro-oxidant mechanisms and the

*Address for correspondence E-mail: sahar_sayed@yahoo.com

September-October 2019 antioxidant defences, contributing to oxidative stress. Thus, reducing intracellular glutathione level, and increasing intracellular lipid peroxidation leading to oxidative damage to proteins and nucleic acids ${ }^{[6]}$.

Much concern has been focused on the defensive effects of antioxidants against oxidative stress damage. Investigators reported that L-carnitine is a compound biosynthesized from the amino acids methionine, and lysine in kidney and liver. It presents at a high concentration in skeletal and cardiac muscles. L-carnitine assists as a cofactor necessary for the transport of long chain fatty acids into the mitochondria for energy production in the peripheral tissues ${ }^{[7]}$. Previous study reported that L-carnitine acts as an

This is an open access article distributed under the terms of the Creative Commons Attribution-NonCommercial-ShareAlike 3.0 License, which allows others to remix, tweak, and build upon the work non-commercially, as long as the author is credited and the new creations are licensed under the identical terms

Accepted 26 July 2019

Revised 15 April 2019

Received 07 January 2019

Indian J Pharm Sci 2019;81(5):834-843 
antioxidant and protectant against oxidative damage in diverse organs including kidney ${ }^{[8]}$. L-carnitine used as a protectant against drug induced nephrotoxicity such as the aminoglycosides, the anticancer drugs, and the contrast medium agents ${ }^{[9]}$. It has been reported that L-carnitine inhibited free radical generation, prevented the damage due to fatty acid $\beta$-oxidation in mitochondria and protected tissues from impairment by renovating oxidized membrane lipids ${ }^{[10]}$. The current study was performed to assess the structural changes in the renal cortex following atorvastatin treatment and the possible protective mechanisms of L-carnitine.

\section{MATERIALS AND METHODS}

Atorvastatin (Lipitor) $40 \mathrm{mg}$ tablets were obtained from Egyptian International Pharmaceutical Industries Company (EIPICO), Egypt. Tablets were ground and freshly dissolved in distilled water. L-carnitine was obtained from Arab Co. for Pharmaceuticals and Medicinal Plants (MEPACO-MEDI Food), Egypt.

\section{Experimental animals:}

Male Wistar rats weighing $200 \pm 3 \mathrm{~g}$ were used in this study. Rats were obtained from the Central Animal House, Faculty of Medicine, Assiut University. Rats were housed and controlled according to the techniques in agreement to the National Institute of Health protocol and Institutional Ethics Committee of Assiut University. Before the beginning of the experiment, rats were set for two weeks for acclimatization to their new environment. Then they were housed in the stainless steel cages at a suitable temperature $\left(24 \pm 1^{\circ}\right)$ and humidity controlled room with 12-h light/dark cycle. They were retained under good illumination. Animals were fed with standard rat pellet, and had free access to water.

\section{Animal groups:}

In this experimental study, 32 male rats were divided into 4 equal groups as follows, group I served as the control group received distilled water. Group II received L-carnitine, $100 \mathrm{mg} / \mathrm{kg}^{[10]}$. Group III received atorvastatin dissolved in distilled water at $80 \mathrm{mg} / \mathrm{kg} / \mathrm{d}$. Group IV received both L-carnitine and atorvastatin at the same doses as given to group II and III rats. The human therapeutic dose of atorvastatin is ranged from $10-80 \mathrm{mg} / \mathrm{d}^{[11]}$. The maximum human therapeutic dose of $80 \mathrm{mg} / \mathrm{kg} / \mathrm{d}$ was used in the current work. The equivalent therapeutic dose for adult male rat was $1.44 \mathrm{mg} / 200 \mathrm{~g}$, which was calculated using the formula of Laurence and Bacharach ${ }^{[12]}$. All drugs were administered orally and daily for $30 \mathrm{~d}$.

\section{Histological technique:}

At the end of the experiment, kidneys from different groups were excised and the right kidneys were fixed in $10 \%$ formalin solution for $24 \mathrm{~h}$. The specimens were processed to prepare $5 \mu \mathrm{m}$ thick paraffin sections and stained with Hematoxylin and Eosin (H and E) and Periodic acid-Schiff (PAS) stains ${ }^{[13]}$.

\section{Histopathological study:}

To determine the changes or damage in kidney morphology, the $\mathrm{H}$ and $\mathrm{E}$ sections were investigated by blinded pathologist to determine the presence of glomerular and tubular damage. Five pieces of kidney section from each group were observed and scored under light microscope. The severity of renal injury score (0-4) was performed by assessing the percentage of glomerulus and cortical renal tubules that revealed abnormalities such as increases of Bowman's space, pyknotic nuclei and tubular dilatation, The histopathological assessment was performed as follows: 0 : none; $1:<5 \% ; 2: 5-25 \% ; 3: 25-75 \%$ and 4: $>75 \%$. All scorings were summed and represented as mean values on the $\operatorname{graph}^{[14]}$.

\section{Immunohistochemical technique:}

Immunohistochemical staining for proliferating cell nuclear antigen (PCNA) and inducible nitric oxide synthase (iNOS) was directed using the avidin-biotin peroxidase according to a previously published technique ${ }^{[15]}$. Three mictometer thick sections obtained from paraffin embedded tissues were deparaffinised, rehydrated and rinsed in tap water. The endogenous peroxidase activity was removed by treatment with methanol comprising $0.03 \%$ hydrogen peroxide for $20 \mathrm{~min}$. Before incubation with primary antibody, sections were incubated with normal serum for $20 \mathrm{~min}$ to block nonspecific antibody. Immunohistochemical staining was carried out using a primary antibody to PCNA, (Clone PC10), mouse monoclonal, Thermo Fischer Scientific, 1:200). Next, the biotinylated goat antimouse $\operatorname{IgG}$ secondary antibody (Abcam, Cambridge, USA, 1:200) was used to detect the primary antibody to PCNA. The primary antibody for iNOS is antiiNOS antibody, rabbit polyclonal antibody (Abcam, Cambridge, USA, 1:200). Subsequently, sections were incubated with biotinylated goat antirabbit IgG secondary antibody (Abcam, Cambridge, USA, 1:100). All sections were stained successively 
with biotinylated $\operatorname{IgG}$ for $10 \mathrm{~min}$ and avidinbiotin horseradish peroxidase complex for $15 \mathrm{~min}$. Visualization of the reaction was carried out by adding the chromogen diaminobenzidine (Dako, Glostrup, Denmark) to slides, which produces a dark brown colour that is detected by light microscopy. Then the slides were washed with distilled water and sections were counterstained with Mayer's haematoxylin. Kidney sections were dehydrated, reduced transparent with xylene, and cover slipped. Slides were observed under a light microscope. The negative controls were run regularly in parallel by omitting the primary antibody. Normal kidney tissues were used as positive controls. The investigation and the photography were conducted at the Mycology and Biotechnology Unit, Al-Azhar University, Cairo, Egypt.

\section{Transmission electron microscopy technique:}

Specimens for electron microscopic study were cut into $1 \mathrm{~mm}^{3}$ pieces and fixed in $2.5 \%$ glutaraldehyde for $24 \mathrm{~h}$. The kidney specimens were then washed in three to four changes of cacodylate buffer $(\mathrm{pH} 7.2)$ for 20 min each. Post fixation was performed in $1 \%$ osmium tetroxide for $2 \mathrm{~h}$. Then, they were washed in four changes of cacodylate buffer for $20 \mathrm{~min}$ each. Dehydration was carried out using ascending grades of alcohol. They were cleared in propylene oxide and then embedded in Epon 812 using a gelatin capsule. The samples were kept in an incubator at $35^{\circ}$ for one day, at $45^{\circ}$ for another day and finally at $60^{\circ}$ for $3 \mathrm{~d}^{[16]}$. The semithin sections, $0.5-1 \mu \mathrm{m}$ were prepared using LKB ultramicrotome and stained with toluidine blue. Ultrathin sections (50 nm thick) from selected areas of trimmed blocks were prepared and collected on copper grids then the ultrathin sections were stained with uranyl acetate for $10 \mathrm{~min}$ and lead citrate for $5 \mathrm{~min}$. Finally, these sections were examined under an electron microscope (Jeol JEM 1010, Japan) at the electron microscopic unit of Faculty of Medicine, Assiut University.

\section{Morphometric and statistical analysis:}

All parameters were measured Using Leica 500 software image analyser (Leica image system Ltd, Cambridge, England). The Mean area percent of PAS positive reaction of the brush borders and basal laminae of the proximal and distal convoluted tubule was measured. The parameters of mean area percent of iNOS and PCNA positive immunoreaction were also measured. Randomly, twenty fields were taken at x 400 magnification. Obtained data of the morphometric results were organized and analysed. Data were summarized as mean \pm standard deviation (SD) and compared using one-way ANOVA followed with posthoc Tukey's test for multiple comparisons between groups using SPSS software 16 (SPSS, Chicago, Illinois, USA). The differences were statistically significant when $\mathrm{p}<0.05$.

\section{RESULTS AND DISCUSSION}

$\mathrm{H}$ and $\mathrm{E}$ stained sections obtained from the control rats (group I) revealed normal appearance of the renal cortex (fig. 1a). The renal cortex consists of the renal corpuscles and the tubules. The renal corpuscles comprised of tuft of capillaries (glomerulus) surrounded by Bowman's capsule. The capsule consists of two layers, the outer parietal and inner visceral layers. The urinary space or Bowman's space exists between the two layers of the capsule. The proximal convoluted tubules are lined by acidophilic cuboidal epithelium. The proximal convoluted tubules with apparent apical brush border and a narrow lumen were observed. The cytoplasm was acidophilic and granular. The nuclei were rounded, basal, and vesicular. However, the distal convoluted tubules were lined with acidophilic cuboidal epithelium and they have wide lumen (fig. 1a).

$\mathrm{H}$ and $\mathrm{E}$ stained sections obtained from L-carnitinetreated group (group II) revealed that the renal corpuscles consist of tuft of glomeruli and Bowman's capsule (fig. 1b). Intact glomeruli with thin walled Bowman's capsules were observed. The proximal convoluted tubules were lined with rounded nuclei, apical brush border and narrow lumen. The distal convoluted tubules were lined with cubical cells, rounded central nuclei and wide lumen (fig. 1b). H and $\mathrm{E}$ stained sections of atorvastatin-treated group (group III) showed some renal corpuscles with atrophied glomeruli and widening of Bowman's space. Some cells of the renal tubules with pyknotic nuclei and vacuolated cytoplasm can be seen. Hemorrhage was observed in the interstitium (figs. 1c-e). $\mathrm{H}$ and $\mathrm{E}$ stained sections of atorvastatin and L-carnitine-treated group (group IV) showed that most of the glomeruli, the proximal and distal convoluted tubules appeared nearly normal. Clearly, conservation of renal tissue and decrease of tubular impairment were observed (fig. 1f).

Semiquantitative analysis showed the result of kidney injury in different studied groups. The atorvastatin treated group results were supported by the significant increase in renal injury score when compared with 


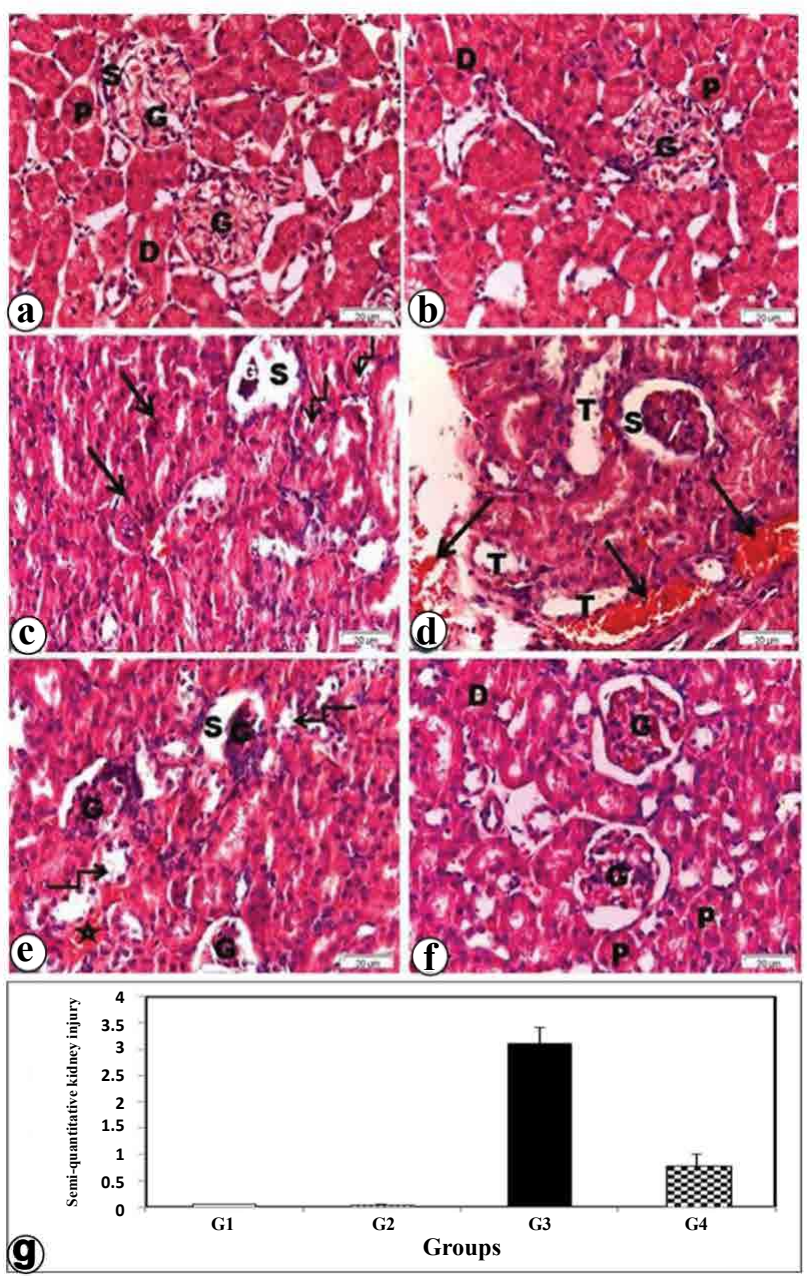

Fig. 1: Photomicrographs of renal cortical sections

(a) Control group showing normal architecture, note: the renal glomeruli (G), surrounded by a narrow Bowman's space (S). The proximal (P) and the distal convoluted tubules (D) can be observed. (b) L-carnitine-treated group showing normal structures of the glomerulus (G), proximal tubules (P) and distal convoluted tubules (D). (c, $d$ and e) Atorvastatin-treated group and (f) L-carnitine and atorvastatin-treated group showing (c) atrophy of the glomerulus $(G)$ with nearly complete loss of glomerular capillaries and widening of Bowman's space (S). Some cortical tubules showed dark acidophilic cytoplasm with pyknotic nuclei (arrows), note: complete loss of brush border of some proximal tubules (curved arrows). (d) Interstitial hemorrhage (arrows), note: enlargement of the Bowman's space (S). Tubular degeneration (T) was observed. (e) Glomeruli (G) with a widened Bowman's space (S). Mild congestion of some peritubular capillaries (star). Vacuolated cytoplasm (curved arrows) are noticed. (f) Nearly normal glomeruli (G), proximal convoluted (P) and distal convoluted tubules (D). $\mathrm{H}$ and $\mathrm{E}, \mathrm{x400}$. (g) Semiquantitative analysis showing result of kidney injury in different groups. The values are expressed as means \pm SD $(p<0.05)$

control ( $\mathrm{p}<0.05$; fig. 1g). Atorvastatin plus L-carnitine treatment led to a decrease in these morphological changes as indicated by a significant improve in renal injury score when compared with atorvastain group alone ( $<<0.05$; fig. $1 \mathrm{~g}$ ).
In control and L-carnitine sections, glycogen exist in the cytoplasm of tubular epithelial cells, the brush borders and the parietal layer of Bowman's capsule (figs. 2a, b), respectively. Rats treated with atorvastatin showed a decrease in PAS positive reaction in the renal tubular cells and the brush borders and an increase in the parietal layer (fig. 2c). Rats given atorvastatin and L-carnitine revealed an increase in PAS positive reactivity in renal tubules with nearly normal brush border. Nearly normal PAS positive basal laminae of parietal epithelium of Bowman's capsules were observed (fig. 2d). Morphometric results of PAS reaction are illustrated in (fig. 2e).

Renal iNOS expression was evaluated by using an immunohistochemical technique. The current results
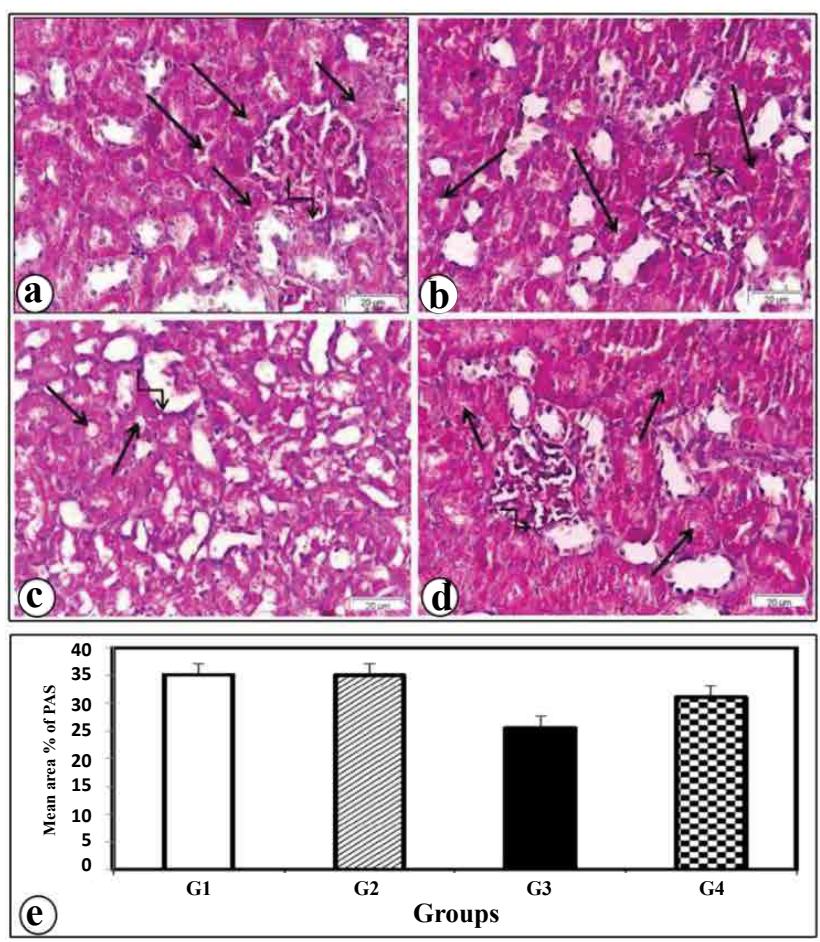

Fig. 2: Renal cortical sections from different studied groups and mean area percentage of PAS

(a) Control group showing multiple tubules with preserved brush border (arrows). PAS stained parietal layer of Bowman's capsule (curved arrow) was observed. (b) L-carnitine group showing intact brush border (arrows) in most of the cortical tubules. PAS stained parietal layer of Bowman's capsule (curved arrow) can be seen. (c) Atorvastatin group showing most of the tubules with loss of brush border (arrows). Increased PAS positive reactivity of basal laminae of the parietal epithelium of Bowman's capsules is detected in some areas of renal corpuscles (curved arrow). (d) Atorvastatin and L-carnitine group showing some tubules with approximately normal brush border (arrows). Nearly normal PAS positive basal laminae of the parietal epithelium of Bowman's capsules is observed (curved arrow). PAS, $x 400$. (e) The mean area percentage of PAS among different studied groups. $\mathrm{P}<0.05$ G1 vs. G3, $\mathrm{p}<0.05$ G1 vs. $G 4$ and $p<0.05, G 3$ vs. G4 
showed strong iNOS immunopositive reaction in atorvastatin-treated group that expressed in most of the renal tubular cells (fig. 3c). Mild iNOS immunopositivity was found in kidney section of atorvastatin and L-carnitine treated group (fig. 3d). In contrast, a weakly iNOS immunopositive reaction was shown in the kidney of control group (fig. 3a) and L-carnitine group (fig. 3b). These findings were confirmed by morphometric analysis of iNOS positive staining in the renal tissue (fig. 3e).

Increased positive PCNA immune reaction in renal tubular cells in atorvastatin-treated group was detected (fig. 4c). Further increased positive PCNA immunereactivity in renal tubular cells was observed in the atorvastatin and L-carnitine-treated group (fig. 4d). However, few PCNA immunostaining in renal tubular cells in the control group (fig. 4a) was seen. No changes were seen to PCNA immunoreactivity in L-carnitine group (fig. 4b) as compared with the control group
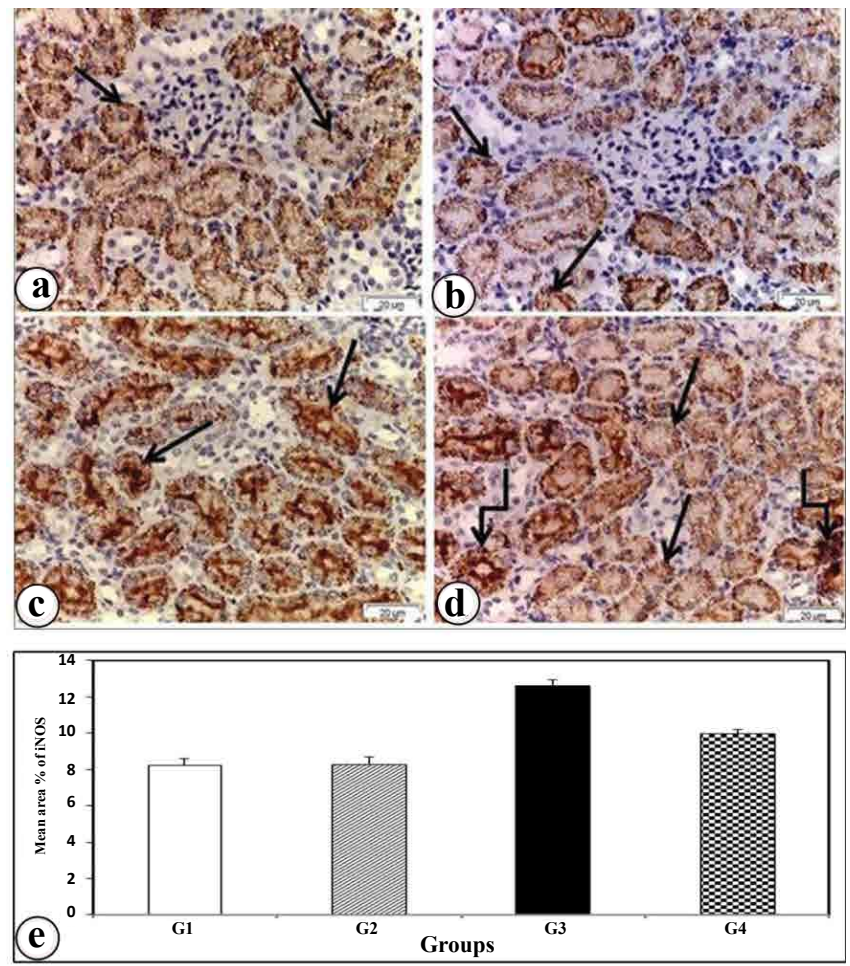

Fig. 3: Representative photomicrographs demonstrating iNOS immunostaining in kidney sections from different groups and mean area percentage of iNOS

(a) The control group showing weak iNOS expression in the renal tubules (arrows). (b) The L-carnitine-treated group showing normal iNOS expression in the renal tubules (arrows). (c) The atorvastatin-treated group showing strong iNOS expression in the renal tubules (arrows). (d) The atorvastatin and L-carnitine-treated group showing mild iNOS expression in the renal tubules (arrows). Few tubules showing strong staining (curved arrows). iNOS immunostaining, $x 400$. (e) The mean area percentage of iNOS among different groups. $P<0.05$ G1 vs. G3, p<0.05 G1 vs. G4 and $p<0.05$ G3 vs. G4

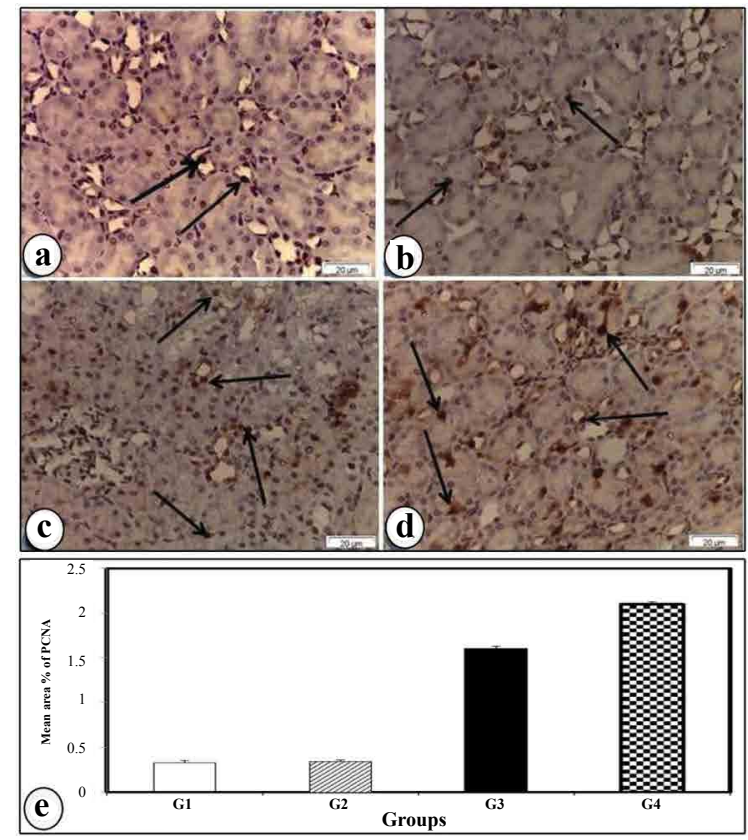

Fig. 4: Representative photomicrographs illustrating PCNA immunostaining in kidney sections of different groups and mean area percentage of PCNA

(a) The control group showing few numbers of positive PCNA immunoreactivity in renal tubular cells (arrows). (b) The L-carnitine-treated group showing few numbers of positive PCNA immunoreactivity in renal tubular cells (arrows). (c) The atorvastatin-treated group showing increased positive PCNA immunoreactivity in renal tubular cells (arrows). (d) The atorvastatin and L-carnitine-treated group showing increased positive PCNA immunoreactivity in renal tubular cells (arrows). PCNA immunostaining, $x 400$. (e) The mean area percentage of PCNA among different groups. $P<0.05$ G1 vs. G3, $p<0.05$ G1 vs. $G 4$ and $p<0.05$ G3 vs. G4

(fig. 4a). These results were confirmed by the morphometric study of PCNA immunoreactivity staining in renal tissues (fig. 4e).

Electron microscopic examination of ultrathin sections of the renal cortex of the control group showed normal architecture of proximal tubular cells and renal corpuscles (fig. 5a-c). The proximal convoluted tubular cells appeared with euchromatic nuclei and numerous tightly packed apical microvilli (fig. 5a, b). The basal plasma membrane revealed infoldings with numerous elongated mitochondria (fig. 5a). The renal corpuscles showed the glomerular capillaries bounded by podocytes. The podocytes had long primary processes which branched to give the secondary foot processes. The later separated by the narrow slits membrane. The podocytes and the glomerular capillaries shared the smooth thinning basement membrane with trilaminar form (fig. 5c).

Electron microscopic examination of ultrathin sections of the renal cortex of the L-carnitine group (group II) 
revealed no tubular or glomerular damage (fig. 6a, b). The proximal convoluted tubules appeared with large, rounded or oval euchromatic nuclei. Many tubular elongated mitochondria between the basal infoldings of the cell membrane were observed. The cells rest on thin basal lamina (fig. 6a). The renal corpuscles revealed glomerular capillaries surrounded by podocytes. The arrangement of secondary processes and uniform thinning of the glomerular basement membrane was detected. The podocytes have large euchromatic nuclei (fig. 6b).

Electron microscopic examination of ultrathin sections of the renal cortex of Atorvastatin treated group (Group III) revealed tubular and glomerular injury (fig. 7a-d). Some proximal convoluted tubules showed electron dense shrunk nuclei. Apparently, increased number of lysosomes was observed. The cytoplasm showed numerous vacuoles of variable sizes and partial loss of microvilli. Clearly, loss of longitudinal arrangement of mitochondria and disorganized basal infoldings were detected (fig. 7a, b). The renal corpuscles revealed congested glomerular capillaries and vacuolated podocytes with irregular nuclei. Fusion of podocyte foot processes and regional thickening of the glomerular basement membrane were observed (fig. 7c, d).

Electron microscopic examination of ultrathin sections of the renal cortex of the atorvastatin- and L-carnitinetreated group (group IV) presented nearly normal structure of proximal tubular cells, podocytes and their processes (fig. 8a, b). Most of the proximal convoluted tubules revealed normal euchromatic nuclei and restoration of the numerous elongated mitochondria (fig. 8a). The renal corpuscle showed thinning of the

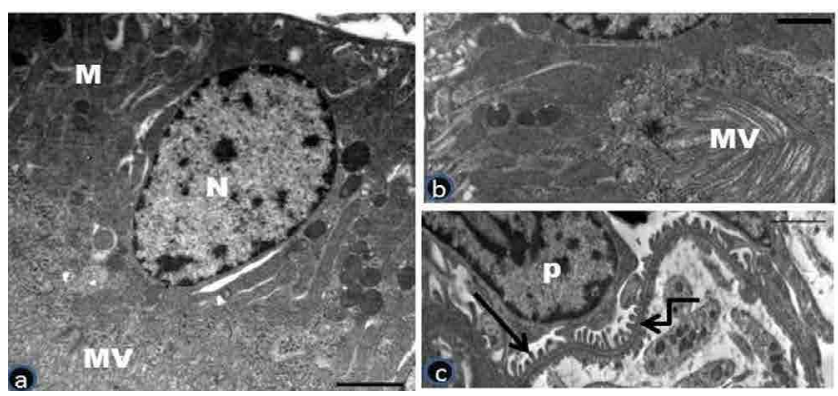

Fig. 5: Electron photomicrographs of the control renal cortical sections

(a) A proximal convoluted tubule cell with an euchromatic nucleus $(N)$. The mitochondria $(M)$ appeared numerous and the brush border of the cells has normal numerous microvilli (MV). (b) A portion of the proximal convoluted tubule with normal microvilli (MV). (c) A portion of glomerulus showed podocyte (P) with thin basal lamina (curved arrow) and normal foot processes (straight arrow). TEM, (a); (b); (c) scale bar $2 \mu \mathrm{m}$
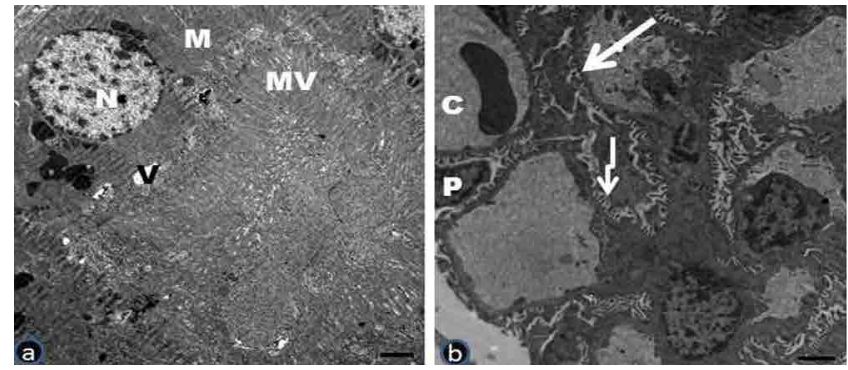

Fig. 6: Electron photomicrographs of the renal cortical sections of L-carnitine-treated group

(a) A portion of the proximal convoluted tubule with an euchromatic nucleus $(\mathrm{N})$. Note, multiple elongated mitochondria (M), numerous microvilli (MV) and few vacuoles (V). (b) The glomerulus showed a regular arrangement of secondary foot processes (curved arrow) and regular thinning of the glomerular basement membrane (straight arrow). Glomerular capillary $(C)$ and normal podocyte $(P)$ were seen. TEM, (a); (b) scale bar $2 \mu \mathrm{m}$

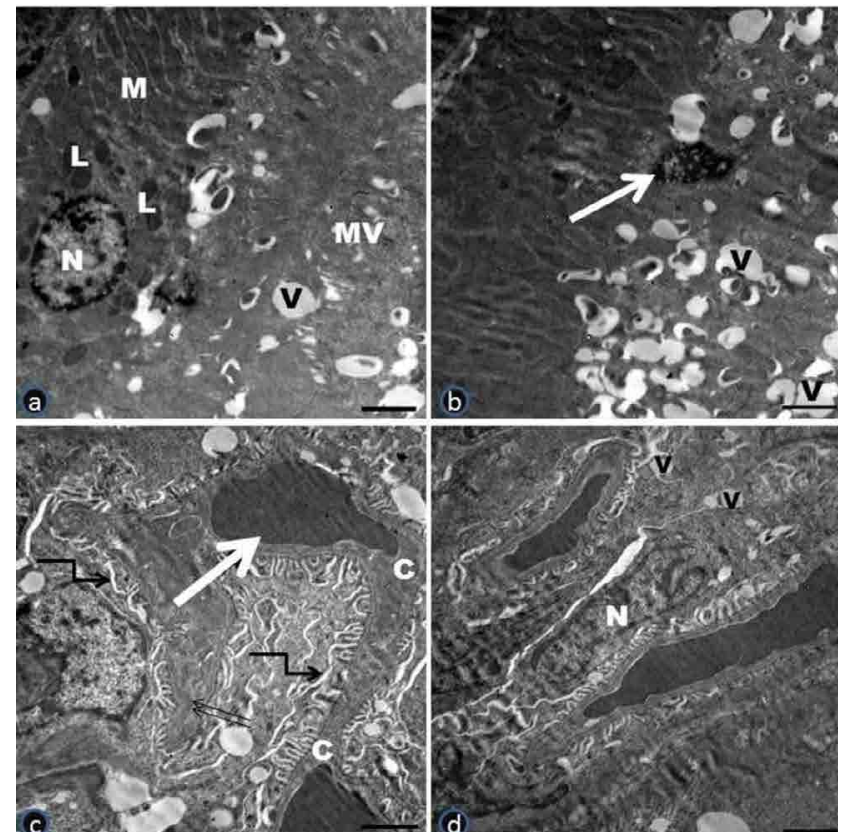

Fig. 7: Electron photomicrographs of the renal cortical sections of atorvastatin-treated group

(a) A part of the proximal convoluted tubule containing a small nucleus $(\mathrm{N})$. The cytoplasm showed numerous vacuoles (V) of variable sizes, partial loss of microvilli (MV), numerous lysosomes (L) and swollen mitochondria (M). (b) A portion of proximal convoluted tubule containing a very small dense pyknotic nucleus (arrow), note: numerous vacuoles (V) and the reduction of basal infoldings with loss of longitudinal arrangement of the mitochondria. (c) The glomerulus showed glomerular capillaries (C) congested with RBCs (arrow). Note, the fusion of podocyte foot processes (curved arrows) and the regional thickening of the glomerular basement membrane (double arrow). (d) The glomerulus showed a podocyte with vacuolated cytoplasm (V) and irregular nucleus (N). TEM, (a); (b); (c); (d) scale bar $2 \mu \mathrm{m}$

glomerular basement membrane. The presence of slightly congested glomerular capillaries was seen (fig. 8b). 


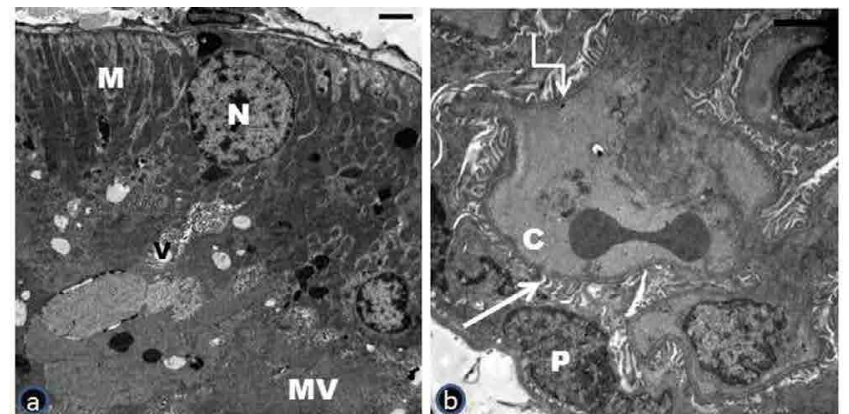

Fig. 8: Electron photomicrographs of the renal cortical sections of atorvastatin and L-carnitine-treated rats

(a) A part of a proximal convoluted tubule showing restoration of the numerous elongated mitochondria $(M)$, the euchromatic nucleus (N), microvilli (MV) and few vacuolations (V). (b) A portion of glomerulus showing moderately normal arrangement of secondary processes (straight arrow) and uniform thinning of the glomerular basement membrane (curved arrow), note: slightly congested glomerular capillary $(C)$ and nearly normal podocyte (P). TEM, (a); (b) scale bar $2 \mu \mathrm{m}$

Principally, atorvastatin is a cholesterol lowering medication broadly recommended for primary and secondary prevention of cardiovascular disease. The kidneys have a remarkable regeneration capability and it is the most competent player amongst all tissues in the body. After kidney injury, some of the living renal tubular cells differentiated and then reenter the cell cycle to produce epithelial cells to renovate the structure and the function of the renal tubular cells ${ }^{[17]}$.

Light microscopic examination of the kidneys of atorvastatin-treated rats revealed degenerative changes in the renal cortex. Many degenerative changes including atrophied glomeruli with widening of their Bowman's spaces. This wide distance might be secondary to shrinkage of the glomerulus. This study illustrated that the proximal convoluted tubules showed vacuolation, pyknotic nuclei and dark acidophilic cytoplasm. In agreement with the present results, some investigators have been reported that the high dose of statin might lead to kidney tubular cell injury ${ }^{[18]}$. Similarly, other researchers suggested that tubular injury lead to tubular atrophy and ultimately end stage renal failure ${ }^{[19]}$. The cytoplasmic vacuolations could be attributed to increasing fluid uptake as a result of altered permeability of the cell membrane as reported in another study ${ }^{[20]}$. It has been reported that pyknosis is a histological feature of apoptosis ${ }^{[21]}$.

In the current study, nitric oxide was measured as an indicator of reactive oxygen species and oxidative stress. Nitric oxide is formed from L-arginine by three isoforms of nitric oxide synthase (NOS). They are the neuronal (nNOS), the endothelial (eNOS) and the inducible NOS (iNOS). iNOS is upregulated in pathological disorders, such as obesity ${ }^{[22]}$. Nitric oxide is considered as a paracrine mediator with several aims that contributed in several physiological and pathological mechanisms. The mechanisms involved the inflammation, immune system, apoptosis and gene regulation $^{[23,24]}$. In this study, iNOS was expressed in the cytoplasm of renal tubule epithelial cells. The more intense expression of iNOS was detected in the atorvastatin-treated group as compared with the control and L-carnitine groups. The present findings were in agreement with those of previous investigators who observed that the iNOS has been recognized as a crucial player in the pathogenesis of metabolic kidney diseases ${ }^{[25,26]}$. Similarly, the upregulation of iNOS expression was observed in the septic kidney tissues ${ }^{[27]}$. Moreover, in rodent models, various investigations stated an elevation of iNOS expression of obesity and diabetes $^{[28]}$. Indeed, nitric oxide produced by iNOS in the tubular cells might induce an increase in oxidative damage and consequently lead to tubular impairment. In our study, the upregulation of iNOS expression was inhibited by treatment with L-carnitine. Significantly, investigators noticed inhibition of iNOS provided an improvement of tubular function by suppressing proteinuria and oxidative stress production ${ }^{[29,30]}$. L-carnitine produced its antioxidant properties through diverse mechanisms, including the scavenging of free radical activity directly or by inhibition of its production. Consequently, keeping the competence of the mitochondrial electron transport chain and exciting the activation of the antioxidant enzymes ${ }^{[31]}$. Moreover, L-carnitine attenuated doxorubicin induced generation of free radicals and improved the functional and structural integrity of the myocardium ${ }^{[32]}$.

PCNA expression is a significant index of renal regeneration. Scientists showed that the expression of PCNA linked with the rates of cellular proliferation and DNA synthesis ${ }^{[33]}$. In this study, the number of PCNA positive cells increased in atorvastatin group as compared with the control and L-carnitine groups. These results were consistent with other studies, which reported that the increased PCNA expression in tubular epithelial cells and interstitial infiltrate specified up regulation of their proliferative rate ${ }^{[34]}$.

The current data revealed that PCNA immunoreactive positive cells further increased in atorvastatin and L-carnitine group. This suggests that kidney cells of rats after $\mathrm{L}$-carnitine treatment have stronger replicative 
activity. In agreement with the current results, the number of PCNA positive cells was elevated five-fold in silymarin plus mycotoxin-treated mice as compared to mycotoxin group ${ }^{[35]}$. The same was observed by other investigators, who stated that the administration of hematopoietic stem cells derived from human umbilical cord significantly increased the number of PCNA positive cells, proposing that umbilical cord CD34+ strongly stimulated tubular cell proliferation however inhibiting cell apoptosis ${ }^{[36]}$.

Evaluating brush border preservation in the proximal tubules is a histochemical marker for monitoring the function of proximal tubule cells. In this study, the proximal tubule cells of atorvastatin group showed partial loss of their brush border, which was proved in ultrathin sections by marked interruption of apical microvilli. Examination of PAS stained sections of this group verified partial or complete loss of brush border in most of the proximal convoluted tubular cells. Moreover, an increase in the number of lysosomes in the same group as compared with control. Definitely, acute renal injury enhanced lysosomal proliferation and activated the autophagy pathway in the proximal tubular cells ${ }^{[37]}$.

Several renal ultrastructural changes in the glomeruli were detected following atorvastatin such as thickened glomerular basement membrane and fusion of podocytes foot processes. Thickening of the basement membrane is an indicator of injury produced due to reactive oxygen species. The current results are consistent with previous investigators, who reported similar results in kidney diseases associated with proteinuria and after cisplatin administration ${ }^{[38]}$. The findings of this study have shown that co-administration of L-carnitine reduced the harmful effect of atorvastatin. This was detected by both light and electron microscopes. Most of the glomeruli were more or less normal and restoration of microvilli was also observed. These findings were supported by PAS stained sections that exhibited nearly normal PAS positive brush border in most of the cortical tubules. A decrease of iNOS reaction and an increase in PCNA immunoreactivity were detected. These findings were in agreement with the previous investigators who reported that L-carnitine has a protective effect as an antiinflammatory and antiapoptotic ${ }^{[39]}$. L-carnitine has physiological functions on fatty acids transport across the inner mitochondrial membrane and it has the properties to scavenge reactive oxygen species ${ }^{[40]}$.
Despite all the deleterious of atorvastatin found in this study as well as in other investigations, some studies deliberated that atorvastatin and other statins are safe to use even at high doses. Other researchers suggested that statins exert a defensive possession in the structures affected by diabetes such as the kidney ${ }^{[41]}$. Atorvastatin induced a nephrotoxic effect at the dose studied in this study, which indicate that it is appropriate to adjust the dose. Significantly, the current results brought the evidence that the mechanism of the defensive effect of L-carnitine is linked to improve cell proliferation and inhibition of iNOS in the kidney. Future investigations should be carried out using the molecular mechanism.

\section{Conflict of interest:}

No conflict of interest between any of the author.

\section{REFERENCES}

1. Soner BC, Inan SY, Guven U, Oktem G, Sahin, AS. Combined treatment with resveratrol prevents the atorvastatin-induced myopathy in rat skeletal muscle. Afr J Pharm Pharmacol 2013;7(18):1114-18.

2. Chung WF, Liu SW, Chang PY, Lin FS, Chen LF, Wu JC, et al. Hyperlipidemia and statins affect neurological outcome in lumbar spine injury. Int $\mathrm{J}$ Environ Res Public Health 2015;12(1):402-13.

3. Chung $\mathrm{YH}$, Lee YC, Chang $\mathrm{CH}$, Lin MS, Lin JW, Lai MS. Statins of high versus low cholesterol-lowering efficacy and the development of severe renal failure. Pharmacoepidemiol Drug Saf 2013;22(6):583-92.

4. Ahmed S, Saber EA, Hamouda AH, Rifaai RA. Structural Changes in the Skeletal Muscle Fiber of Adult Male Albino Rat Following Atorvastatin Treatment. The Possible Mechanisms of Atorvastatin Induced Myotoxicity. J Cytol Histol 2017;8:442.

5. Shepherd J, Hunnighake DB, Barter P, Mckenney JM. Hutchinson HG. Guidelines for lowering lipids to reduce coronary artery disease risk: A comparison of rosuvastatin with atorvastatin, pravastatin and simvastatin for achieving lipid lowering goals. Am J Cardiol 2003;91:11C-19C.

6. Pal S, Ghosh M, Ghosh S, Bhattacharyya S, Sil PC. Atorvastatin induced hepatic oxidative stress and apoptotic damage via MAPKs, mitochondria, calpain and caspase12 dependent pathways. Food Chem Toxicol 2015;83:36-47.

7. Binienda ZK, Ali SF. Neuroprotective role of 1-carnitine in the 3-nitropropionic acid induced neurotoxicity. Toxicol Lett 2001;125:67-73.

8. Sener G, Paskaloğlu K, Satiroglu H, Alican I, Kaçmaz A. Sakarcan A. L-Carnitine ameliorates oxidative damage due to chronic renal failure in rats. J Cardiovasc Pharmacol 2004;43(5):698-705

9. Jafari A, Dashti-Khavidaki S, Khalili H, Lessan-Pezeshki M. Potential nephroprotective effects of 1-carnitine against druginduced nephropathy: a review of literature. Expert Opin Drug Saf 2013;12:523-43.

10. Mescka CP, Rosa AP, Schirmbeck G, da Rosa TH, Catarino F, de Souza LO, et al. L-carnitine prevents oxidative stress in the 
brains of rats subjected to a chemically induced chronic model of MSUD. Mol Neurobiol 2016;53:6007-17.

11. Bersot TP. Drug Therapy for Hypercholesterolemia and Dyslipidemia. In: Brunton LL, Chabner BA, Knollmann BC, editors. Goodman \& Gilman's The Pharmacological Basis of Therapeutics. 12th eds. New York: McGraw Hill Medical; 2011. p. 877-78.

12. Laurence DR, Bacharach AL. Evaluation of drug activities and pharmacometrics. London: Academic Press; 1964. p.135.

13. Suvarna K, Layton C, Bancroft J. Theory and Practice of Histological Techniques. 7th eds. Staining methods. London: Churchill Livingstone; 2008, p. 147-150, 263-325.

14. Zhao B, Fei J, Chen Y, Ying YL, Ma L, Song XQ, et al. Vitamin $\mathrm{C}$ treatment attenuates hemorrhagic shock related multi-organ injuries through the induction of heme oxygenase-1. BMC Complement Altern Med 2014;14:442.

15. Forbes JM, Hewitson TD, Becker GJ, Jones CL. Ischemic acute renal failure: Long-term histology of cell and matrix changes in the rat. Kidney Int 2000;57:2375-85.

16. Glauret A, Lewis P. Biological Specimen Preparation for Transmission Electron Microscopy. 1st eds. William Street, Princeton, New Jersey: Princeton University Press; 1998.

17. De Broe ME. Tubular regeneration and the role of bone marrow cells: 'stem cell therapy' - a panacea? Nephrol Dial Transplant 2005;20:2318-20.

18. Acharya T, Huang J, Tringali S, Frei CR, Mortensen EM, Mansi IA. Statin use and the risk of kidney disease with longterm follow-up (8.4-year study). Am J Cardiol 2016;117:64755.

19. Lin CE, Chang WS, Lee JA, Chang TY, Huang YS, Hirasaki $\mathrm{Y}$, et al. Proteomics analysis of altered proteins in kidney of mice with aristolochic acid nephropathy using the fluorogenic derivatization-liquid chromatography-tandem mass spectrometry method. Biomed Chromatogr 2017;32:e4127.

20. Shaffie NM, Morsy FA, Ali AG, Sharaf HA. Effect of Craway, Coriander and Fennel on the structure of Kidney and Islets of Langerhan in Alloxan-Induced Diabetic Rats: Histological and Histochemical Study. J Am Sci 2010;2:27-40.

21. Newman M. Cells Tissues and Organs. In Fundamentals of Ecotoxicology. The Science of Pollution .4th ed. Boca Raton, Florida, United States: CRC Press, 2014. p. 209-234.

22. Anand P, Stamler JS. Enzymatic mechanisms regulating protein S-nitrosylation: implications in health and disease. $\mathrm{J}$ Mol Med 2012;90(3):233-44.

23. Förstermann U, Sessa WC. Nitric oxide synthases: regulation and function. Eur Heart J 2012;33(7):829-37,837a-837d.

24. Lee J, Bae EH, Ma SK, Kim SW. Altered nitric oxide system in cardiovascular and renal diseases. Chonnam Med J 2016;52(2):81-90.

25. Nordquist L, Liss P, Fasching A, Hansell P, Palm F. Hypoxia in the diabetic kidney is independent of advanced glycation end-products. Adv Exp Med Biol 2013;765:185-93.

26. Slyvka Y, Malgor R, Inman SR, Ding J, Heh V, Nowak FV. Antioxidant diet and sex interact to regulate NOS isoform expression and glomerular mesangium proliferation in Zucker diabetic rat kidney. Acta Histochem 2016;118(2):183-93.

27. Li G, Jia J, Ji K, Gong X, Wang R, Zhang X, et al. The neutrophil elastase inhibitor, sivelestat, attenuates sepsisrelated kidney injury in rats. Int J Mol Med 2016;38(3):76775.

28. Kuloglu T, Aydin S. Immunohistochemical expressions of adropin and inducible nitric oxide synthase in renal tissues of rats with streptozotocin-induced experimental diabetes. Biotech Histochem 2014;89(2):104-10.

29. Kadkhodaee M, Zahmatkesh M, Sadeghipour HR, Eslamifar A, Taeb J, Shams A, et al. Proteinuria is reduced by inhibition of inducible nitric oxide synthase in rat renal ischemiareperfusion injury. Transplant Proc 2009;41:2907-09.

30. Schneider R, Meusel M, Betz B, Kersten M, Möller-Ehrlich $\mathrm{K}$, Wanner $\mathrm{C}$, et al. Nitric oxide induced regulation of renal organic cation transport after renal ischemia-reperfusion injury. Am J Physiol Renal Physiol 2011;301:F997-F1004.

31. Surai PF. Antioxidant action of carnitine: molecular mechanisms and practical applications. Vet Sci 2015;2:66-84.

32. Mustafa HN, Hegazy GA, Awdan SAE, Abdel Baset M. Protective role of CoQ10 or L-carnitine on the integrity of the myocardium in doxorubicin induced toxicity. Tissue Cell 2017;49(3):410-26.

33. Li Y, Xiong W, Yang J, Zhong J, Zhang L, Zheng J, et al. Attenuation of inflammation by Emodin in lipopolysaccharideinduced acute kidney injury via inhibition of Toll-like receptor 2 signal pathway. Iran J Kidney Dis 2015;9(3):202-08.

34. Nakopoulou L, Stefanaki K, Salpigidis K, Boletis J, Papadakis $\mathrm{J}$, Zeiss PM, et al. The value of proliferating cell nuclear antigen (PCNA)/cyclin in the assessment of cell proliferation in glomerulonephritis. Histol Histopathol 1997;12:655-62.

35. He Q, Kim J, Sharma RP. Silymarin protects against liver damage in BALB/ c mice exposed to fumonisin B1 despite increasing accumulation of free sphingoid bases. Toxicol Sci 2004;80:335-42.

36. Shalaby RH, Rashed LA, Ismaail AE, Madkour NK, Elwakeel $\mathrm{SH}$. Hematopoietic stem cells derived from human umbilical cord ameliorate cisplatin-induced acute renal failure in rats. Am J Stem Cells 2014;3(2):83-96.

37. Hamouda AH, Taha HA, Ahmad RF. Study of the Effect of Aristolochic Acid on Mice Kidney and the Effect of Withdrawal: Histological and Immunohistochemical Study. J Cytol Histol 2018;9(2):504.

38. Mahdy A, El-Morshdy K. Role of losartan on the renal cortex damage induced by cisplatin in adult male albino rats. Egypt $\mathrm{J}$ Histol 2014;37:480-91.

39. Izgüt-Uysal VN, Ağaç A, Derin N. Effect of L-Carnitine on carrageenan-induced inflammation in aged rats. Gerontology 2003;49:287-92.

40. Mescka C, Moraes T, Rosa A, Mazzola P, Piccoli B, Jacques $\mathrm{C}$, et al. In vivo neuroprotective effect of L-carnitine against oxidative stress in maple syrup urine disease. Metab Brain Dis 2011;26:21-28.

41. Vlad A, Vlad M, Petrica L, Ursoniu S, Gadalean F, Popescu $\mathrm{R}$, et al. Therapy with atorvastatin versus rosuvastatin reduces urinary podocytes, podocyte-associated molecules, and proximal tubule dysfunction biomarkers in patients with type 2 diabetes mellitus: a pilot study. Ren Fail 2017; 39(1):112-19. 